\title{
Surrogate formulation for diesel and jet fuels using the minimalist functional group (MFG) approach
}

\author{
Abdul Gani Abdul Jameel ${ }^{\mathrm{a},{ }^{*}}$, Nimal Naser ${ }^{\mathrm{a}}$, Abdul-Hamid Emwas ${ }^{\mathrm{b}}$ and S. Mani \\ Sarathy ${ }^{\mathrm{a}, *}$ \\ ${ }^{a}$ King Abdullah University of Science and Technology, Clean Combustion Research \\ Center, Thuwal 23955, Saudi Arabia \\ ${ }^{\mathrm{b}}$ King Abdullah University of Science and Technology, Imaging and Characterization \\ Core Laboratory, Thuwal 23955, Saudi Arabia
}

\begin{abstract}
Surrogate fuels aim to reproduce real fuel combustion characteristics in order to enable predictive simulations and fuel/engine design. In this work, surrogate mixtures were formulated for three diesel fuels (Coryton Euro and Coryton US-2D certification grade and Saudi pump grade) and two jet fuels (POSF 4658 and POSF 4734) using the minimalist functional group (MFG) approach, a method recently developed and tested for gasoline fuels. The diesel and jet fuel surrogates were formulated by matching five important functional groups, while minimizing the surrogate components to two species. Another molecular parameter, called as branching index (BI) which denotes the degree of branching was also used as a matching criterion. The present works aims to test the ability of the MFG surrogate methodology for high molecular weight fuels (e.g., jet and diesel). ${ }^{1} \mathrm{H}$ Nuclear Magnetic Resonance (NMR) spectroscopy was used to analyze the composition of the groups in diesel fuels, and those in jet fuels were evaluated using the molecular data obtained from published literature. The MFG surrogates were experimentally evaluated in an ignition quality tester (IQT,) wherein ignition delay times (IDT) and derived cetane number (DCN) were measured. Physical properties namely, average molecular weight (AMW), density; and thermochemical properties namely, heat of combustion and $\mathrm{H} / \mathrm{C}$ ratio was also compared. The results show that the MFG surrogates were able to reproduce the combustion properties of the above fuels, and we demonstrate that fewer species in surrogates can be as effective as more complex surrogates. We conclude that the MFG approach can radically simplify the surrogate formulation process, significantly reduce the cost and time associated with the development of chemical kinetic models, and facilitate surrogate testing.
\end{abstract}

Keywords: surrogates, functional group, ignition delay time (IDT), ${ }^{1} H$ NMR spectroscopy 


\section{Introduction}

Practical fuels contain hundreds of individual molecules and modeling their combustion behavior is highly challenging. Usually mixtures of two or more species called as surrogates, are employed to emulate various physical, thermochemical and combustion properties of their respective target fuels. This makes it easier to develop chemical kinetic models required for design, simulation and optimization of engine combustion. Significant research and development has been made in surrogate formulation towards gasolines [1-3], diesel [4,5], jet fuels [6,7] and also for heavy fuel oils [8,9]. Different methodologies $[3,4,10,11]$ have been proposed for the selection of surrogate components and their blending to formulate mixtures. Gasoline surrogates may be formulated by matching its antiknock behavior against that of an nheptane and 2,2,4-trimethylpentane mixture (i.e., primary reference fuel, PRF) measured in a cooperative fuels research (CFR) engines. The PRF composition that produces a similar knock (i.e. octane rating) as the target gasoline is specified as the PRF surrogate [2]. For diesels, a mixture of 2,2,4,4,6,8,8-heptamethylnonane (HMN) and n-hexadecane is used as the PRF to match compression ignition delay time (IDT) characteristics (i.e., cetane rating). Other approaches [12] for surrogate formulation add species from each hydrocarbon class to create a surrogate palette containing several (usually 3-7) species. To date, the majority of surrogate formulation methodologies are an engineering art with limitations, as recently discussed in [13], when considering experimental uncertainties.

This work extends upon a recently developed surrogate formulation methodology [14] developed by our team and tested on gasoline fuels. In that work [14], surrogates were formulated by matching functional groups readily identified and quantified by analytical techniques such as ${ }^{1} \mathrm{H}$ NMR spectroscopy. The novelty of the 
minimalist functional group (MFG) approach lies in the focus of matching fundamental and elementary molecular parameters in the target fuel, rather than focusing on broad molecular classes. In addition, the number of species in the surrogate mixtures is minimized to one or a maximum of two. Besides functional groups, another structural parameter, the branching index (BI) was also used as a target criterion. BI represents the degree (and quality) of branching and has been defined and explained in detail in our previous work [15]. It consists of a position index (PI) term that explains why isomers having similar functional group distribution have different properties.

While conventional surrogate formulation methodologies enhance surrogate complexity by adding more species, the MFG approach shows that surrogates containing fewer species formulated by replicating the fuels functional groups can reproduce the behavior of more complex surrogates. Our previous work [14] focused on gasoline fuels, which have long ignition delays and lower molecular weights. In this work, we test the MFG surrogate formulation methodology on diesel and jet fuels, which are significantly more reactive and are higher molecular weight. The notable differences in chemical reactivity and physical properties of the fuels studied herein differentiate this study from prior work [14] and further validate the flexibility of the MFG approach.

\section{Background}

Real fuels contain hundreds of different molecules that are composed of a smaller number of building blocks (i.e., functional groups) that dictate their physical and chemical properties. Abdul Jameel et al. [15] demonstrated the ability to predict DCN of hydrocarbon fuels by a multiple linear regression model trained on six functional 
groups. The RON and MON of oxygenated fuels have also been successfully predicted using an artificial neural network trained by the functional group approach [16]. Dooley et al. [7] disassembled surrogates into three functional groups $\left(\mathrm{CH}_{3}, \mathrm{CH}_{2}\right.$ and $\mathrm{C}_{6} \mathrm{H}_{3} \mathrm{X}_{2} \mathrm{CH}_{2}$ ) and demonstrated that these groups determine the radical pool formation. The type and proportion of the functional groups present control the chemical reactions regardless of the parent molecules from which these were generated. The common building blocks of paraffinic fuels are $\mathrm{CH}_{3}$ and $\mathrm{CH}_{2}$ groups, and it has been experimentally shown [17] that the ratio of $\mathrm{CH}_{2} / \mathrm{CH}_{3}$ can be correlated with the low temperature alkylperoxy radical reactivity; furthermore, the parameter $\frac{\mathrm{CH}_{2}}{\mathrm{CH}_{3}} *\left(\mathrm{CH}_{2}+\mathrm{CH}_{3}\right)$ controls IDT regardless of the species in the mixture. Functional group based pseudo-component surrogates were developed for high molecular weight paraffinic fuels by Mehl et al. [18]. The propensity for soot formation of oxygenated fuels has also been analyzed using a structural group contribution approach [19].

In this work, the selected functional groups for surrogate groups were limited to five, namely, paraffinic $\left(\mathrm{CH}_{3}, \mathrm{CH}_{2}\right.$ and $\left.\mathrm{CH}\right)$, aromatic $\mathrm{C}-\mathrm{CH}$ groups, and naphthenic $\mathrm{CH}-\mathrm{CH}_{2}$. The MFG approach for surrogate formulation was tested on three diesel fuels: Coryton Euro and Coryton US-2D, both non-oxygenated certification diesels, and Saudi pump grade diesel; and two jet fuels: POSF 4734 (S8) and POSF4658 (Jet-A). The functional groups present in diesels were evaluated by high resolution ${ }^{1} \mathrm{H}$ NMR spectroscopy and those in jet fuels were calculated using GC-MS. Experiments were conducted in an ignition quality tester (IQT) at various temperature conditions to compare IDT behavior of real fuels and various surrogates.

\section{Experimental methods}

\section{1 ${ }^{1}$ H NMR spectroscopy}


Functional groups in complex hydrocarbon fuels like diesel and jet fuel can be conveniently analyzed using ${ }^{1} \mathrm{H}$ NMR spectroscopy. It is a powerful technique that can help differentiate the different types of $\mathrm{H}$ atoms in the fuel. NMR spectra are shown by means of chemical shifts and the molecular structure can be visualized by the position and intensity of these shifts. The various functional groups can then be identified by their characteristic peaks and quantified followed by peak integration. A significant advantage when using ${ }^{1} \mathrm{H}$ NMR spectroscopy is that distinct signals are displayed for functional groups of similar nature, thereby aiding their identification.

All ${ }^{1} \mathrm{H}$ NMR experiments of the three diesels were carried out at $298 \mathrm{~K}$. The NMR spectrometer used was Bruker 700 AVANAC III. The Coryton Euro and US2D diesels were obtained from Coryton Advanced Fuels Ltd (UK) and the Saudi diesel was obtained from a gas station in Saudi Arabia. $50 \mu 1$ of each diesel fuel was dissolved in $700 \mu \mathrm{l}$ of solvent $\left(\mathrm{CDCl}_{3}\right)$ and then $550 \mu 1$ was transferred to $5 \mathrm{~mm}$ NMR tubes. 128 scans were recorded for collecting each spectrum and a standard $1 \mathrm{D} 90^{\circ}$ pulse sequence was used. Tetramethylsilane (TMS) was used as the internal standard to adjust the chemical shifts. Topspin 2.1 software was used for data collection and Mestrenova 12 was used for spectral analysis. All of the spectra were processed five times after adjusting the baseline and visual phasing, and the average values were used. The ${ }^{1} \mathrm{H}$ NMR spectra of the three diesels are shown in Fig. 1.

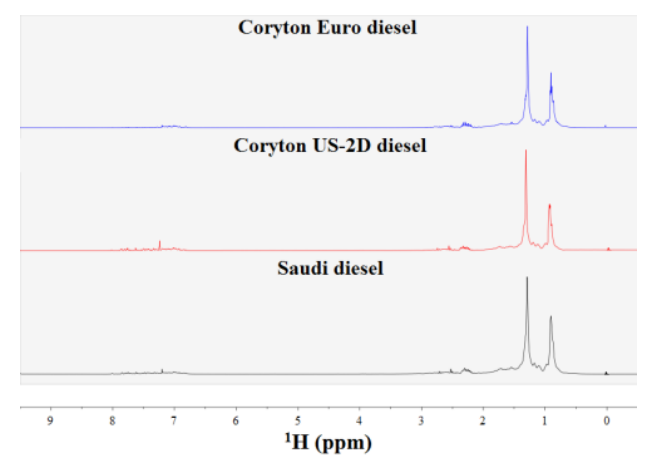

Figure 1. ${ }^{1} \mathrm{H}$ NMR spectra of the three diesel samples analyzed 


\subsection{Functional group determination}

The functional groups were identified by chemical shift assignments derived from $[21,22]$. The ${ }^{1} \mathrm{H}$ NMR spectra enables quantitative estimation of different $\mathrm{H}$ types in a given fuel. For example, the fraction of $\mathrm{H}$ atoms appearing in paraffinic $\mathrm{CH}_{2}$ groups can be calculated by the area under the $\mathrm{CH}_{2}$ peaks in the region (0.94-1.39 and 2.64$2.88 \mathrm{ppm}$ ) divided by sum of areas under all peaks. Paraffinic $\mathrm{CH}_{2}$ groups (in weight $\%$ ) is then calculated by multiplying the groups molecular weight (14) with the quantity of $\mathrm{H}$ atoms (in mole \%) determined previously and then dividing by 2 i.e., the number of $\mathrm{H}$ atoms. $\mathrm{CH}_{3}, \mathrm{CH}_{2}$ and $\mathrm{CH}$ groups appearing in alpha position to aromatics were used to calculate the contribution of quaternary aromatic carbons as these cannot be directly inferred from the ${ }^{1} \mathrm{H}$ NMR spectra. The detailed procedure and the equations needed to calculate the functional groups in weight $\%$ is available in our previous work [15].

The functional groups in POSF 4658 and 4734 jet fuels were calculated from the pure components identified using GC-MS from [23,24]. The molecules were broken down to their constituent functional groups and then summed up to yield the functional group distribution for the entire fuel. Ideally, the functional group should be obtained

from ${ }^{1} \mathrm{H}$ NMR spectra, but the jet fuels investigated here were obtained from the literature studies that did not perform NMR analysis. Therefore we had to rely on the literature GC-MS data to obtain the necessary functional groups.

\subsection{Surrogate formulation}

The functional group calculation of the above fuels was followed by a survey of potential species that can effectively match the target functional groups. Average molecular weight (AMW) of fuels has an important effect on their physical properties, so surrogate components were shortlisted such that they fall within the molecular 
range of the target fuels. Two surrogate mixtures were formulated for Coryton Euro diesel. The first surrogate contained four molecules (one from each hydrocarbon class in the fuel) and is named as the multicomponent (MC) surrogate. The second surrogate contains two molecules and is named as the MFG surrogate. Both these surrogates mimic the functional groups closely. This was carried out to test the minimalist approach proposed in the work, i.e., potential of a simple surrogate to reproduce reactivity of a more complex surrogate. For the other fuels, only one MFG surrogate was formulated, as shown in Fig. 2.

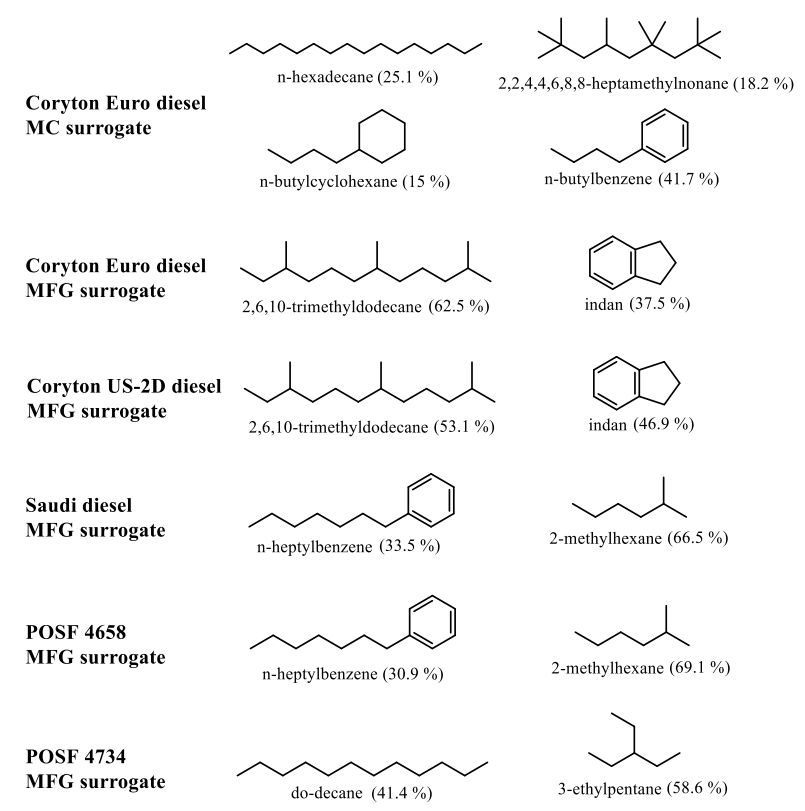

Figure 2. Surrogate species used to represent the diesel and jet fuels. The composition given in the brackets are in mole $\%$.

The MC surrogate of Coryton Euro diesel was formulated using n-hexadecane, HMN, n-butylcyclohexane and n-butylbenzene. For the MFG surrogates, a single molecule that possesses all the functional groups of the fuel was attempted (see Supplementary Material), but such molecules are not commercially available for experimentation, so two molecules were permitted. Coryton Euro diesel has an appreciable quantity of all five functional groups and its MFG surrogate was represented by indan and 2,6,10-trimethyldodecane. Coryton US-2D diesel has 
slightly more aromatic (22.1 wt \%) and naphthenic groups (9.6 wt \%) and its MFG surrogate was also represented by indan and 2,6,10-trimethyldodecane, albeit it contains slightly more indan than the Euro diesel MFG surrogate. The Saudi diesel sample has a negligible quantity of naphthenic groups (1.4 wt \%) and therefore these functional groups were not considered. The MFG surrogate for Saudi diesel was formulated using n-heptylbenzene and 2-methylhexane. POSF 4658 jet fuel is very similar to Saudi diesel with a high content (18.5 wt \%) of aromatic groups and negligible naphthenic content $(2.5 \mathrm{wt} \%)$; therefore, the surrogate also consists of $\mathrm{n}$ heptylbenzene and 2-methylhexane. POSF 4734 contains no aromatic groups and neglible amount of napthenes. Its surrogate was formulated with n-dodecane and 3ethylpentane. Figure 3 compares the functional groups in the surrogates against those in their respective target fuels. The BI comparison of the fuels and the surrogates is reasonable and is reported in Table 1 . BI of diesel fuels was evaluated from using the expression developed for BI of real fuels in [15]. BI of jet fuels was calculated using the compositional data from GC-MS [23,24]. 


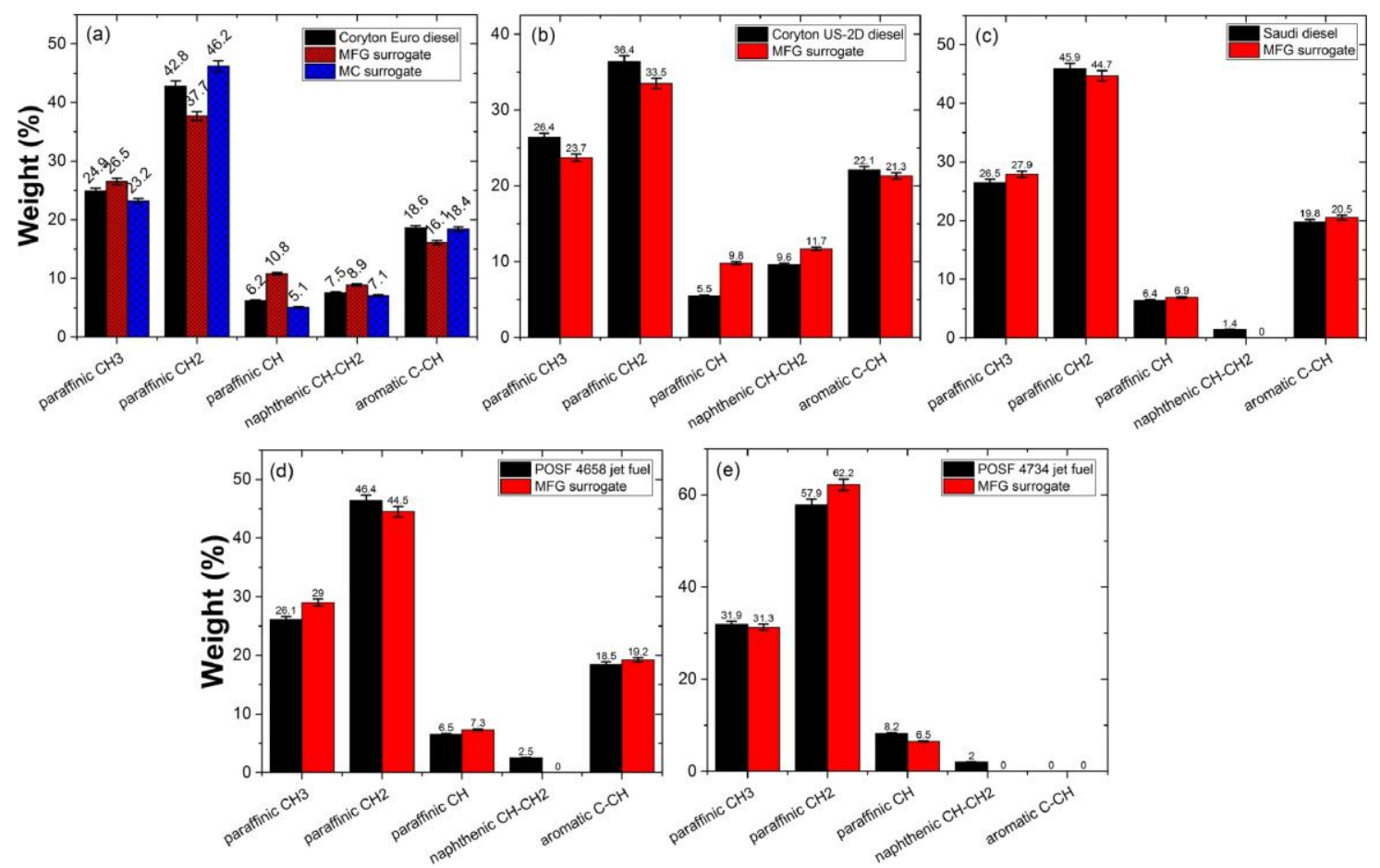

Figure 3. Functional group comparison of MFG surrogates and their target fuels.

\section{Table 1}

BI comparison

\begin{tabular}{cccc}
\hline Name & \multicolumn{3}{c}{ BI (no unit) } \\
\cline { 2 - 4 } & Fuel & MFG & MC \\
surrogate & surrogate \\
\hline Cory. Euro & 0.78 & 0.91 & 0.70 \\
Cory. US-2D & 0.79 & 0.94 & \\
Saudi diesel & 0.51 & 0.45 & \\
POSF 4658 & 0.39 & 0.42 & \\
POSF 4734 & 0.25 & 0.29 & \\
\hline
\end{tabular}

\subsection{Ignition quality tester (IQT)}

The KAUST IQT, a constant volume combustion chamber designed to characterize fuels like diesel as per the ASTM standard D6890 [25], was used to assess the global chemical reactivity of the MFG surrogates. It has an internal chamber volume of 0.21 L with an inward opening single hole S-type pintle nozzle for liquid fuel injection. The chamber is filled with air as oxidizer, which is pressurized to $21.37 \pm 0.07$ bar. A calibration procedure is carried out to obtain the standard temperature where the average of 3 IDT measurements of $n$-heptane provides an IDT value of $3.78 \pm 0.01$ 
ms. The measured IDT combines physical processes (atomization, evaporation, and mixing) and gas-phase chemical kinetic processes that lead to ignition. The beginning of ignition is obtained with a gradient method as discussed in [26,27], which accounts for the low temperature heat release (LTHR) exhibited by some fuels. High temperature heat release (HTHR) can also be determined by the gradient method with the use of two line tangents (LT). The first LT is the point at which pressure recovers and the second LT is at the maximum slope of pressure rise as shown in [26]. The difference in time between the start of ignition and the start of injection is referred to as the IDT. The temperature dependent IDT of two diesel fuels and their surrogates was also measured between the temperature range of $833-673 \mathrm{~K}$ and compared. The IDT measured are the average of 32 injections in with the error bars indicating standard deviation. The reproducibility errors associated with DCN measurements are well defined in the ASTM standard D6890 [25] and are not discussed in this work.

The IQT IDT is a combination of physical and chemical ignition delay. Computations performed in [28] indicated that physical delay times $\sim 1.0 \mathrm{~ms}$ and experiments performed in [29] indicated that physical delay times were consistent among different fuels tested in [29].

DCN measurements are conducted at one specific standard condition and do not capture the behavior of surrogate fuels at other temperatures. In order to assess the performance of surrogates at lower temperature conditions, temperature sweeps were conducted. IDT has an exponential dependence on temperature and power law dependence on pressure in the range of 1-3 [30]. A recent work [31] has shown that for the ASTM standard pressure condition, if the IDTs at low temperatures are matched, their octane sensitivities are also similar. The results in [30] indicate that fuels with similar octane sensitivities have similar pressure exponents. Therefore, if 
the real and surrogate fuel has matching IDTs at different temperature conditions, it is reasonable to expect that the surrogate matches other metrics not considered as part of this study.

\section{Results \& Discussion}

\subsection{Physical and thermochemical properties}

The functional groups in molecules have been shown to affect their physical and thermochemical properties (viscosity [32], density [32]), heat capacity and heat of formation $[33,34]$ ). The molecular building blocks (i.e. the functional groups) in a fuel have a strong correlation with its properties [35]. Functional groups, when matched, will most likely lead to surrogates with properties similar to fuels. In the present work density, AMW, heat of combustion and $\mathrm{H} / \mathrm{C}$ ratio of the developed MFG surrogates were compared against the fuels and are shown in Fig. 4. Surface tension, kinematic viscosity, and other physical-chemical of the real fuels are not available, so such comparisons are not included in this study.
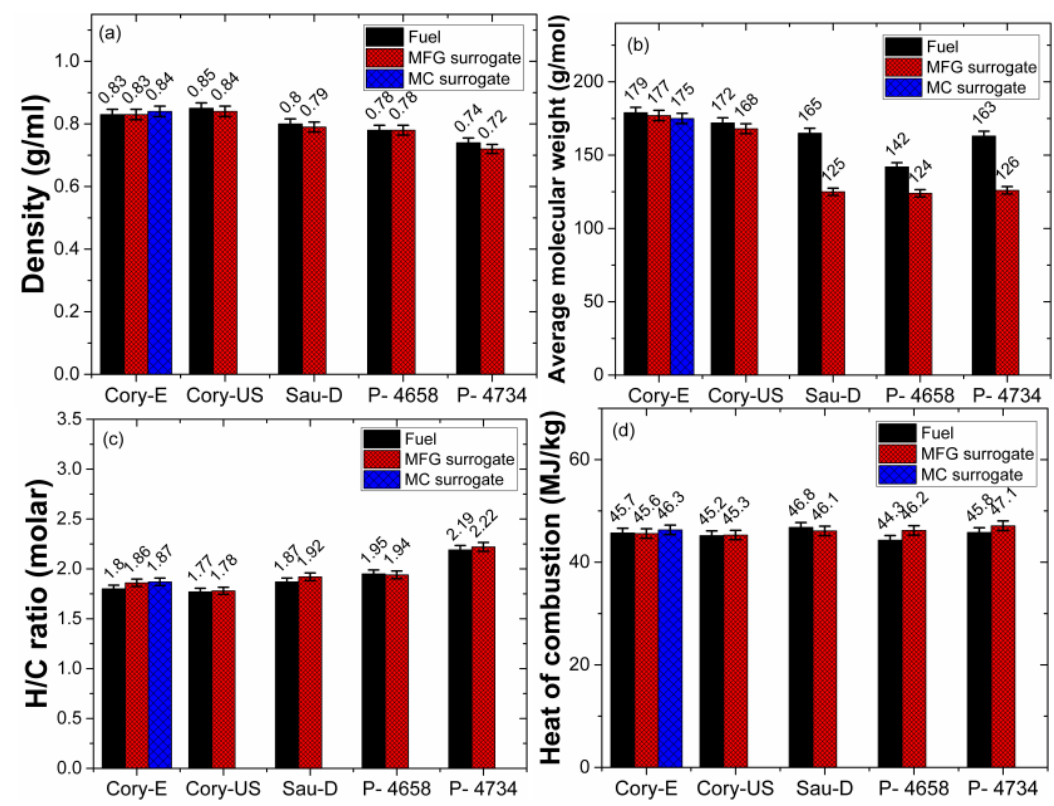

Figure 4. Physical and thermochemical properties: Comparison between MFG surrogates and target fuels. 
The AMW of the diesels was calculated by the distillation curve method in [36] and other properties were taken from the fuels certificate of analysis. The distillation curves are provided in the Supplementary Material. Jet fuel properties were taken from $[6,7,23,24]$. Heat of combustion and density values of pure components in the MFG surrogates were sourced from NIST database [37]. The mixture properties were calculated using linear-by-mass rules. Figure 4 shows a very good comparison of fuel properties of MFG surrogates with the fuels, except AMW of the jet fuels and Saudi diesel where there is 15-20\% difference.

\subsection{IQT ignition delay time}

Experimental measurement of IDT of the fuels and the surrogates was carried out to validate the MFG methodology. Pressure traces of the MFG surrogates compared against their target fuel along with their IDT are shown in Fig. 5. The pressure traces of POSF 4658 and POSF 4734 was estimated based on IDT obtained from IQT experiments performed by [6,7]. The time of ignition (SoIgn) and time of injection (SoInj) are also depicted.
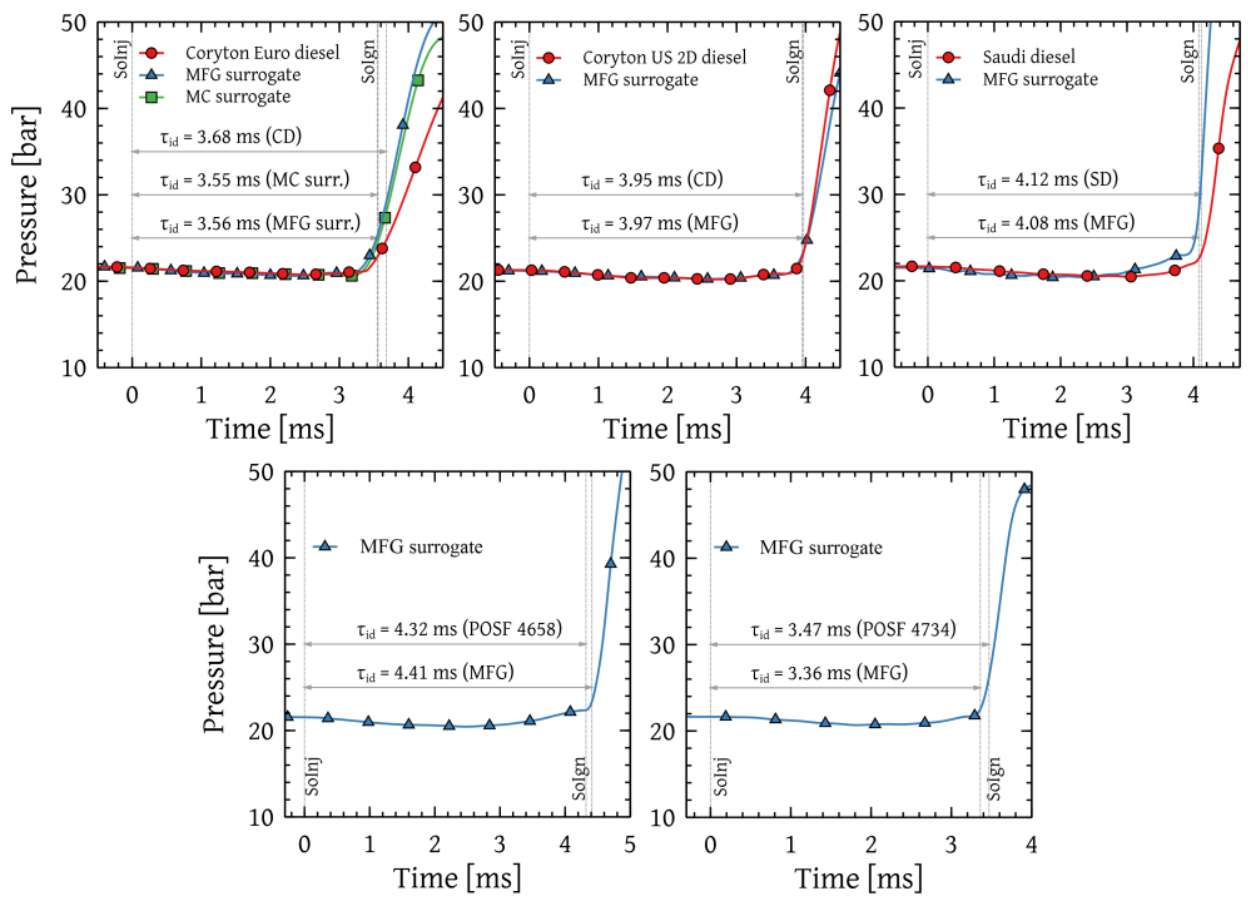
Figure 5. Pressure traces the MFG surrogates and their target fuels from the IQT. Pressure traces of POSF 4658 and POSF 4734 not shown as they were not provided in $[6,7]$.

The similar IDT of the diesel and jet fuels compared to the MFG surrogates indicates similar chemical reactivity. IDT differences for the fuels and the MFG surrogates were less than $5 \%$. IDT are similar for Saudi diesel $(4.12 \mathrm{~ms})$ and POSF 4658 jet fuel $(4.32 \mathrm{~ms})$, and their respective surrogates. This is rationalized by the fact that these two fuels have similar functional group distribution, thereby highlighting the dependence of fuel reactivity on functional groups. The IDT of the complex four components MC surrogate of Coryton diesel is close to that of the two component MFG surrogate. This shows that even simple surrogates can emulate the behavior of more complex surrogates when their functional groups match. The DCN of fuels and MFG surrogates were calculated from their IDTs and are reported in Table 2. The difference in DCN for the fuels and all the surrogates are less $5 \%$.

Table 2

DCN comparison

\begin{tabular}{cccc}
\hline Name & \multicolumn{3}{c}{ DCN (no unit) } \\
\cline { 2 - 4 } & Fuel & MFG & MC \\
surrogate & surrogate \\
\hline Cory. Euro & 55.2 & 56.8 & 57.1 \\
Cory. US-2D & 51.7 & 51.4 & \\
Saudi diesel & 49.8 & 50.2 & \\
POSF 4658 & 47.1 & 46.8 & \\
POSF 4734 & 58.7 & 59.6 & \\
\hline
\end{tabular}

The measurement of DCN based on the ASTM standard provides a single condition for comparing ignition behavior. This limits the temperature range for studying ignition behavior, so it was imperative to test several target fuels and their surrogates at non-standard conditions. The IDT measurements at temperatures lesser than the DCN temperature were obtained at the ASTM standard pressure and the temperature was varied from $833-673 \mathrm{~K}$ at steps of $20 \mathrm{~K}$. The IQT has a maximum operating 
initial temperature of $860 \mathrm{~K}$. The IDT measurements were made at the standard IQT operating pressure of 21.3 bar where NTC behavior is expected to be observed above $860 \mathrm{~K}$, which cannot be achieved due to equipment limitations as mentioned above. Additionally, many studies [38] have shown that IDTs at high temperatures are virtually the same for many fuels. In the present work, the focus was on low temperature region because this is the most sensitive to fuel composition and the hardest to match with surrogate formulations. The temperature dependent IDT of Coryton Euro and Coryton US-2D diesels, and their respective surrogates, were obtained in the IQT, as shown in Fig. 6. Similar IDT indicate that the reactivity of the fuel and the MFG surrogates are the comparable across the temperature range studied.

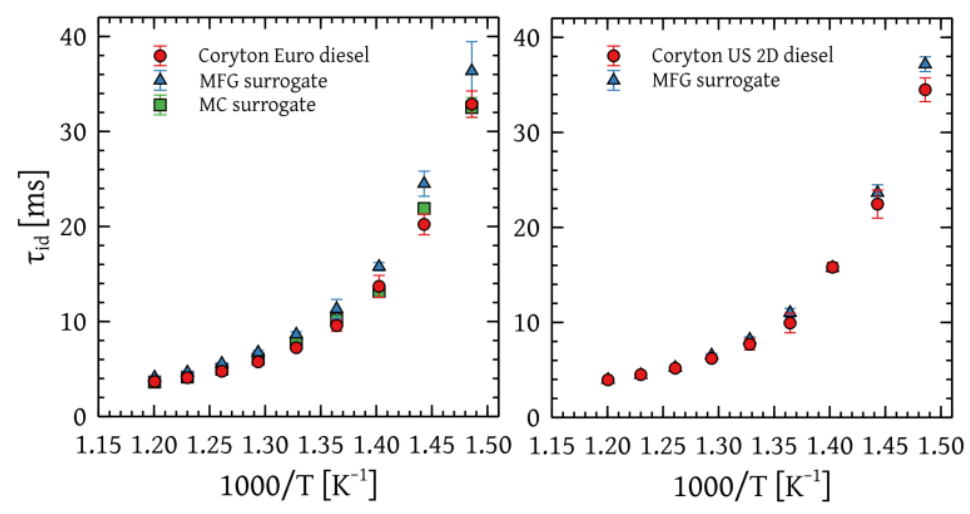

Figure 6. IDT measured at various temperatures for Coryton Euro and Coryton US2D diesels and their surrogates measured in the IQT.

\section{Conclusion}

This work extended validation of the minimalist functional group (MFG) approach for formulating surrogates to diesel and jet fuels. Five functional groups representing paraffinic, naphthenic, and aromatic molecular parameters along with Branching index (BI) were selected as the targets for surrogate formulation. High-resolution ${ }^{1} \mathrm{H}$ NMR was used to analyze the various functional groups in the three diesels studied. For the jet fuels, GC-MS was used to calculate the functional groups. The number of 
components used to represent the MFG surrogates was minimized to two, so as to simplify surrogate formulation procedure and for an unambiguous test of the MFG approach. Physical and thermochemical properties of the novel MFG surrogates were able to emulate the target fuels. The IDT of MFG surrogates and fuels was experimentally measured in an IQT and an excellent agreement was obtained for the conditions studied here. This study together with previous work [14] concludes that surrogates containing a minimal number of species while matching functional groups of the target fuel show great potential for successfully emulating real fuel combustion characteristics of gasoline, diesel, and jet fuels. It is not yet known if other metrics (e.g., magnitude of LTHR, combustion phasing, mixture stratification, emissions) would be as well matched as IDT measured by IQT, so further work is needed to test the validity of the MFG approach in surrogate formulation across a broad range of realistic combustion conditions.

\section{Acknowledgement}

This work was supported by Saudi Aramco under the FUELCOM Program and by King Abdullah University of Science and Technology (KAUST). The work was also funded by KAUST competitive research funding awarded to the Clean Combustion Research Center.

\section{References}

[1] S.M. Sarathy, G. Kukkadapu, M. Mehl, W. Wang, T. Javed, S. Park, M.A. Oehlschlaeger, A. Farooq, W.J. Pitz, C.-J. Sung, Proc. Combust. Inst. 35 (2015) 249-257.

[2] V.S. Bhavani Shankar, M. Sajid, K. Al-Qurashi, N. Atef, I. Alkhesho, A. Ahmed, S. Chung, W. Roberts, K. Morganti, M. Sarathy, in: SAE Tech. Pap. (2016) 2016-01-0748.

[3] A. Ahmed, G. Goteng, V.S.B. Shankar, K. Al-Qurashi, W.L. Roberts, S.M. Sarathy, Fuel. 143 (2015) 290-300. 
[4] C.J. Mueller, W.J. Cannella, T.J. Bruno, B. Bunting, H.D. Dettman, J.A. Franz, M.L. Huber, M. Natarajan, W.J. Pitz, M.A. Ratcliff, K. Wright, Energy \& Fuels. 26 (2012) 3284-3303.

[5] C.J. Mueller, W.J. Cannella, J.T. Bays, T.J. Bruno, K. DeFabio, H.D. Dettman, R.M. Gieleciak, M.L. Huber, C.-B. Kweon, S.S. McConnell, W.J. Pitz, M.A. Ratcliff, Energy \& Fuels. 30 (2016) 1445-1461.

[6] S. Dooley, S.H. Won, M. Chaos, J. Heyne, Y. Ju, F.L. Dryer, K. Kumar, C.-J. Sung, H. Wang, M.A. Oehlschlaeger, R.J. Santoro, T.A. Litzinger, Combust. Flame. 157 (2010) 2333-2339.

[7] S. Dooley, S.H. Won, S. Jahangirian, Y. Ju, F.L. Dryer, H. Wang, M.A. Oehlschlaeger, Combust. Flame. 159 (2012) 3014-3020.

[8] A.G. Abdul Jameel, A.M. Elbaz, A.-H. Emwas, W.L. Roberts, S.M. Sarathy, Energy \& Fuels. 30 (2016) 3894-3905.

[9] A.M. Elbaz, A. Gani, N. Hourani, A.-H. Emwas, S.M. Sarathy, W.L. Roberts, Energy \& Fuels. 29 (2015) 7825-7835.

[10] M. Mehl, J.Y. Chen, W.J. Pitz, S.M. Sarathy, C.K. Westbrook, Energy \& Fuels. 25 (2011) 5215-5223.

[11] S.M. Sarathy, A. Farooq, G. Kalghatgi, Prog. Energy Combust. Sci. (2017) 142. "in press"

[12] A. Violi, S. Yan, E.G. Eddings, A.F. Sarofim, S. Granata, T. Faravelli, E. Ranzi, Combust. Sci. Technol. 174 (2002) 399-417.

[13] P.B. Govindaraju, M. Ihme, Combust. Flame. 188 (2018) 337-356.

[14] A.G. Abdul Jameel, N. Naser, G. Issayev, J. Touitou, M.K. Ghosh, A.-H. Emwas, A. Farooq, S. Dooley, S.M. Sarathy, Combust. Flame,. 192(2018), 250-271.

[15] A.G. Abdul Jameel, N. Naser, A.-H. Emwas, S. Dooley, S.M. Sarathy, Energy \& Fuels. 30 (2016) 9819-9835.

[16] A.G. Abdul Jameel, V. Van Oudenhoven, A.-H. Emwas, S.M.Sarathy, Energy \& Fuels 32(2018) 6306--6329

[17] S.H. Won, S. Dooley, P.S. Veloo, H. Wang, M.A. Oehlschlaeger, F.L. Dryer, Y. Ju, Combust. Flame. 161 (2014) 826-834.

[18] M. Mehl, W.J. Pitz, S.M. Sarathy, C.K. Westbrook, Int. J. Chem. Kinet. 44 (2012) 257-276.

[19] P. Pepiotdesjardins, H. Pitsch, R. Malhotra, S. Kirby, A. Boehman, Combust. Flame. 154 (2008) 191-205.

[20] Bruker User Library https://www.bruker.com/service/informationcommunication/nmr-pulse-program-lib/bruker-user-library.html

[21] A. Sarpal, Fuel. 80 (2001) 521-528.

[22] B. Basu, G.S. Kapur, A.S. Sarpal, R. Meusinger, Energy \& Fuels. 17 (2003) 1570-1575.

[23] J.A. Widegren, T.J. Bruno, Thermal Decomposition Kinetics of the Aviation Turbine Fuel Jet A, Ind. Eng. Chem. Res. 47 (2008) 4342-4348.

[24] M.L. Huber, B.L. Smith, L.S. Ott, T.J. Bruno, Energy \& Fuels. 22 (2008) 1104-1114.

[25] ASTM D6890 Standard Test Method for Determination of Ignition Delay and Derived Cetane Number ( DCN ) of Diesel Fuel Oils by Combustion in a Constant Volume Chamber, 2013.

[26] N. Naser, S.Y. Yang, G. Kalghatgi, S.H. Chung, Fuel. 187 (2017) 117-127.

[27] S.Y. Yang, N. Naser, S.H. Chung, J. Cha, Effect of Temperature, SAE Int. J. Fuels Lubr. 8 (2015) 2015-01-9074. 
[28] G.E. Bogin Jr, A. DeFilippo, J.Y. Chen, G. Chin, J. Luecke, M.A. Ratcliff, B.T. Zigler, and A.M. Dean, 2010. NREL/CP-540-46738 (2010).

[29] J. L. Mendelson, Ignition quality tester characterization with pure component and conventional navy fuels, Ph.D. thesis, University of Maryland, College Park (2016).

[30] Singh, E., Badra, J., Mehl, M. and Sarathy, S.M., Energy \& Fuels, 31(2017), pp.1945-1960.

[31] N. Naser, S. M. Sarathy, S.H. Chung, Fuel 2018 (accepted)

[32] H. Yuan, B. Yang, J. Yang, J Am Oil Chem Soc 86 (2009) 375-382.

[33] T. Thuy, D. Allen, Fuel. 64 (1985) 1754-1759.

[34] S.W. Benson, F.R. Cruickshank, D.M. Golden, G.R. Haugen, H.E. O’Neal, S. Rodgers, R. Shaw, R. Walsh, Chem. Rev. 69 (1969) 279-324.

[35] A.G. Abdul Jameel, Y. Han, O. Brignoli, S. Telalović, A.M. Elbaz, H.G. Im, W.L. Roberts, S.M. Sarathy, J. Anal. Appl. Pyrolysis. 127 (2017) 183-195.

[36] V.K. Rao, M.F. Bardon, Ind. Eng. Chem. Process Des. Dev. 24 (1985) 498500.

[37] NIST chemistry Webbook, NIST Stand. Ref. Database Number 69, available at <http://webbook.nist.gov/>.

[38] S.M. Sarathy, A. Farooq, G.T. Kalghatgi, Prog. Energy Combust. Sci. 65(2018),67-108. 


\section{List of Figure Captions}

Figure 1. ${ }^{1} \mathrm{H}$ NMR spectra of the three diesel samples analyzed

Figure 2. Surrogate species used to represent the diesel and jet fuels. The composition given in the brackets are in mole \%.

Figure 3. Functional group comparison of MFG surrogates and their target fuels.

Figure 4. Physical and thermochemical properties: Comparison between MFG surrogates and target fuels.

Figure 5. Pressure traces of diesel and jet fuels and their respective MFG surrogates from the IQT. Pressure traces of POSF 4658 and POSF 4734 not shown as they were not provided in $[6,7]$.

Figure 6. IDT measured at various temperatures for Coryton Euro and Coryton US2D diesels and their surrogates measured in the IQT.

\section{List of Table Captions}

Table 1. BI comparison

Table 2. DCN comparison 


\section{Supplementary Material}

Potential single molecule surogates

Coryton Euro Diesel<smiles>CCC(C)CCCC(C)CCc1cccc2c1CC2</smiles><smiles>CCCCCC(C)CCc1c(C)ccc2c1CC2</smiles><smiles>CCCCC(C)C(C)CCCc1c(C)c(C)cc2c1CC2</smiles>

Coryton US-2D diesel<smiles>CCCC(C)CCCc1c(C)ccc2c1CCC2</smiles><smiles>CCC(C)CCCc1c(C)c(C)cc2c1CCC2</smiles><smiles>CCCCC(C)Cc1c(C)cc(C)c2c1CCC2</smiles>

Saudi diesel<smiles>CCCCCC(C)CCc1ccccc1C</smiles><smiles>CCCC(C)CCc1ccccc1C</smiles><smiles>Cc1cc2c(c(CCCCCC(C)C)c1C)C2</smiles>

POSF 4658<smiles>CCC(C)CCC(C)CCc1ccccc1</smiles><smiles>Cc1ccccc1CCCCCC(C)C</smiles><smiles>CCC(C)CCCc1cccc(C)c1C</smiles>

POSF 4734<smiles>CC(C)CCCCCC(C)C</smiles><smiles>CCCC(C)CC(C)CCC</smiles><smiles>CCCC(C)CCC(C)C</smiles>

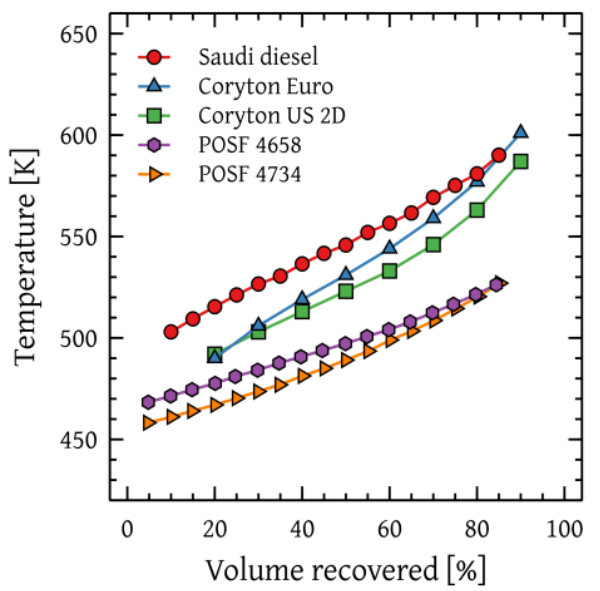

Figure. S1. Distillation curves of real fuels 